\title{
ANÁLISE DOS DESLIZAMENTOS DE MASSA NO “MORRO DO BUMBA" ATRAVÉS DE IMAGENS SATÉLITE.
}

\author{
Francisco Afonso Cavalcanti Júnior ${ }^{1}$ \\ Larissa Piffer Dorigon ${ }^{2}$
}

\begin{abstract}
RESUMO
O presente trabalho tem por finalidade analisar o evento extremo de deslizamento de massa ocorrido em abril de 2010 no Morro do Bumba, Estado do Rio de Janeiro. Neste estudo de caso foram utilizadas imagens de satélites a fim de explicar os condicionantes climáticos atuantes no momento do ocorrido e a repercussão desse evento na alteração da paisagem. As imagens utilizadas foram dos satélites Goes e Mateosat, dados pluviométricos do Inmet e obras bibliográficas que tratam do tema. Ao realizar a análise conjunta dos dados pluviométricos e das imagens de satélite foi possível identificar, principalmente a partir das disposições das nuvens, que durante o episódio de chuvas intensas em Niterói em abril de 2010 o sistema atuante era a ZCAS que associadas as fortes chuvas causadas pela ZCIT, dias antes, e que já havia saturado o solo ocasionou o deslizamento de massa. As imagens orbitais auxiliaram na análise da paisagem após o evento extremo de forte precipitação em um terreno densamente acidentado e ocupado, por isso o deslizamento de massa não pode ser visto apenas de uma ótica natural, pois em muitos casos a combinação de forte precipitação, alta declividade e ação antrópica pode dinamizar e até mesmo acelerar os processos naturais, ampliando a sua magnitude.
\end{abstract}

PALAVRAS-CHAVE: Deslizamento de massa. Imagens de satélite. Alteração da paisagem.

\section{ANALYSIS OF MASS IN THE SLIPS " MORRO BUMBA " VIA SATELLITE IMAGES}

\section{ABSTRACT}

This study aims to analyze the extreme event of landslide occurred in April 2010 in the Morro do Bumba, State of Rio de Janeiro. In this specific study satellite images were used to explain the climatic conditions acting at the time of the incident and the impact of this event in the landscape change. The images used were from Goes and Mateosat satellites, rainfall data from Inmet and bibliographical papers that deal with the subject. When performing the analysis of rainfall data and satellite images we were able to identified, mainly from the provisions of the clouds, which during the episode of heavy rain in Niterói in April 2010 the acting system was ZCAS that in association with heavy rains caused by ZCIT, days before, and had already saturated the soil caused the landslide. The satellite images helped in the analysis of the landscape after the extreme event of heavy rains in a hilly and densely occupied land, so the landslide can not be seen only from a natural perspective, due to in many cases

\footnotetext{
${ }_{1}^{1}$ Mestrando, Universidade Estadual Paulista - UNESP/FCT. afonso.jr1@hotmail.com

${ }^{2}$ Mestranda, Universidade Estadual Paulista - UNESP/FCT. laridorigon@hotmail.com
} 
the combination of heavy rainfall, high slope and human action can streamline and even accelerate the natural processes, expanding its magnitude.

KEYWORDS: Landslip. Satellite images. Changing the landscape.

\section{ANÁLISIS DE LA MISA EN LA SLIPS " MORRO BUMBA " VIA IMÁGENES DE SATÉLITE.}

\section{RESUMÉN}

Este estudio tiene por meta analizar el caso extremo de deslizamiento del suelo que hubo en abril de 2010 en la ubicación del Morro do Bumba, Estado de Río de Janeiro (Brasil). En este estúdio específico fue usado imágenes de satélite para explicar las condiciones climáticas que actuaron en el momento del incidente y el impacto de este evento en el cambio del paisaje. Las imágenes usas fueran de los satélites Goes y Mateosat, datos de precipitación del Inmet y obras bibliográficas que tratan el tema. Al realizar el análisis conjunto de los datos de precipitación y las imágenes de satélite se pudo identificar, principalmente de las disposiciones de las nubes, que durante el episodio de fuertes lluvias en Niterói en abril de 2010 el sistema de actuación fue la ZCAS que asocidas a las fuertes lluvias causadas por la ZCIT, días antes, y que ya habían saturado el suelo, causó el deslizamiento del suelo. Las imágenes de satélites ayudan en el análisis del paisaje después del evento extremo de las fuertes lluvias en una tierra montañosa y densamente ocupada, por lo que el deslizamiento de suelo no se pueden ver sólo desde el punto de vista natural, porque en muchos casos la combinación de fuertes lluvias, alta pendiente y la acción humana pueden agilizar e incluso acelerar los procesos naturales ampliando su magnitud.

PALABRAS-CLAVE: Deslizamiento del suelo. Imagenes de satélite. Cambio del paisaje.

\section{INTRODUÇÃO}

No mês de abril de 2010 o estado do Rio de Janeiro, especialmente a cidade de Niterói, foi enfoque de muitos noticiários nacionais e internacionais. Durante os dias 5 e 8 do referido mês ocorreram uma série de deslizamentos no bairro Viçoso Jardim, periferia da cidade de Niterói/RJ.

Este incidente foi amplamente divulgado pelos meios de comunicação como o desmoronamento da encosta do "Morro do Bumba", tendo um saldo de quase cinquenta mortos e muitas famílias desabrigadas.

Habitualmente, nos meses mais quentes do ano, a região sudeste sofre intensas e constantes entradas de sistemas frontais, fato que acarreta altos índices pluviométricos. No entanto, o mês de abril do ano de 2010 pode ser considerado como um evento extremo, devido à grande quantidade de chuvas que ocorreram, e que aglutinada à fatores sociais e urbanos, ocasionaram esse "acidente".

Neste sentido, este trabalho, de forma bem sintética, apresentará dados de precipitação deste recorte temporal e local, além de imagens de satélites a fim de explicar os condicionantes climáticos atuantes naquele momento e a repercussão 
desse evento na paisagem do bairro do Viçoso Jardim, especificamente na encosta do "Morro do Bumba".

\section{MÉTODO DE ANÁLISE}

Notícias e relatos encontrados em jornais, revistas e noticiários on-line, como a reportagem intitulada "Chuva causa mortes e provoca estragos e desabamentos no RJ" $(\mathrm{G} 1,2010)^{3}$ relatam que as chuvas tiveram início na noite do dia 5 de abril e que o maior e mais intenso deslizamento ocorreu no dia 6.

De acordo com dados obtidos junto ao site do INMET $^{4}$ (Instituto Nacional de Meteorologia) nota-se que durante todo o mês de abril de 2010 as chuvas se concentraram entre os dias 5 e 10, além dos 3 últimos dias do mês (Figura 1).

Destaca-se assim, o dia 6, como sendo o de maior concentração pluviométrica, praticamente $180 \mathrm{~mm}$ e o dia 5 , como sendo o primeiro a apresentar precipitação durante este episódio.

Figura 1: Gráfico de chuva acumulada 24h, abril de 2010.

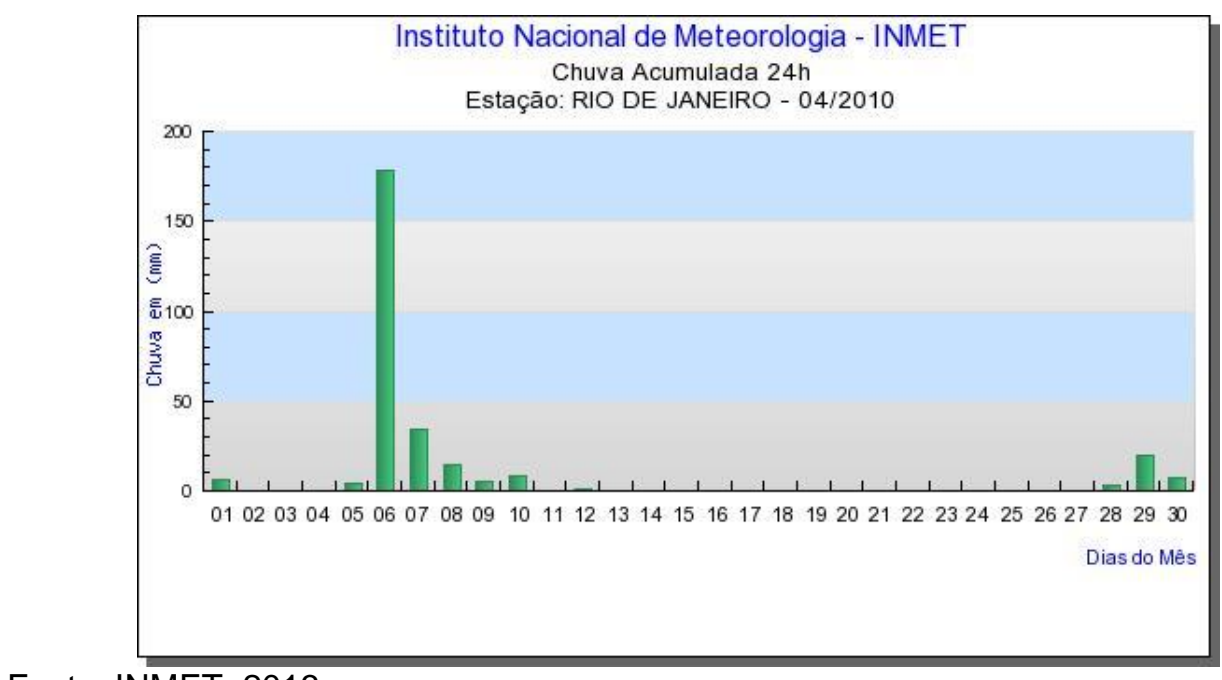

Fonte: INMET, 2013

Através da análise de uma sequência de imagens do satélite Goes 10 e Meteosat 9, projeção retangular e setor América + África, obtidas junto ao site do

${ }^{1}$ http://g1.globo.com/rio-de-janeiro/noticia/2013/12/chuva-causa-mortes-e-provoca-estragos-edesabamentos-no-rj.html

2http://www.inmet.gov.br/sim/gera graficos.php 
CPTEC/INPE ${ }^{5}$ foi possível identificar alguns mecanismos climáticos que atuaram durante esse episódio de evento extremo (Figuras 2, 3, 4 e 5).

Figura 2: Imagem do Satélite Goes e Meteosat, 5 de abril de 2010 às 9h

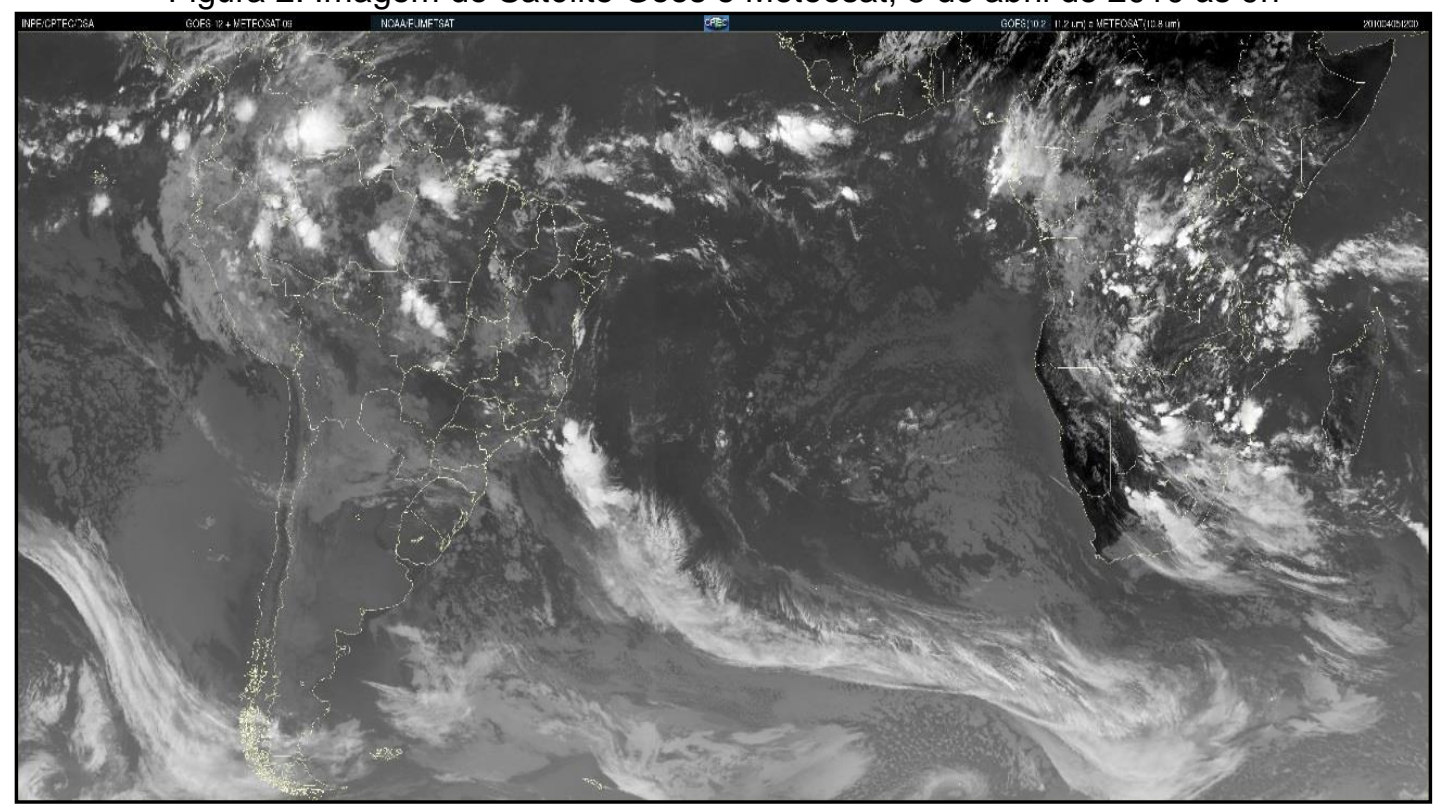

Fonte: INPE, http://satelite.cptec.inpe.br/acervo/goesmet_anteriores15.jsp?i=br, acesso em 7 de dezembro de 2013.

$\mathrm{Na}$ figura 2, é possível observar a formação de uma banda com grande quantidade de nuvens devido a junção das existentes na porção equatorial do país (ZCIT) como as formadas pela entrada de uma possível massa de ar polar (formação de uma frente fria, uma vez que nota-se o vórtice característico de frentes). Assim sendo, no dia 5 os dados de precipitação acumulada registraram os primeiros índices pluviométricos desta sequência de dias.

No dia 6, dia do deslizamento da encosta do "Morro do Bumba" e também o de maior registro de chuvas, observa-se, de acordo com a figura 3 , novamente a configuração anterior, com nuvens por toda a região norte e sudeste do país. Além disso, nota-se uma quantidade expressiva de nuvens concentradas sobre a região do Estado do Rio de Janeiro, fato este que pode ter ocasionado o alto índice pluviométrico deste dia específico.

\footnotetext{
${ }^{5}$ http://satelite.cptec.inpe.br/acervo/goesmet_anteriores15.jsp?i=br
} 
Figura 3: Imagem do Satélite Goes e Meteosat, 6 de abril de 2010 às 9h

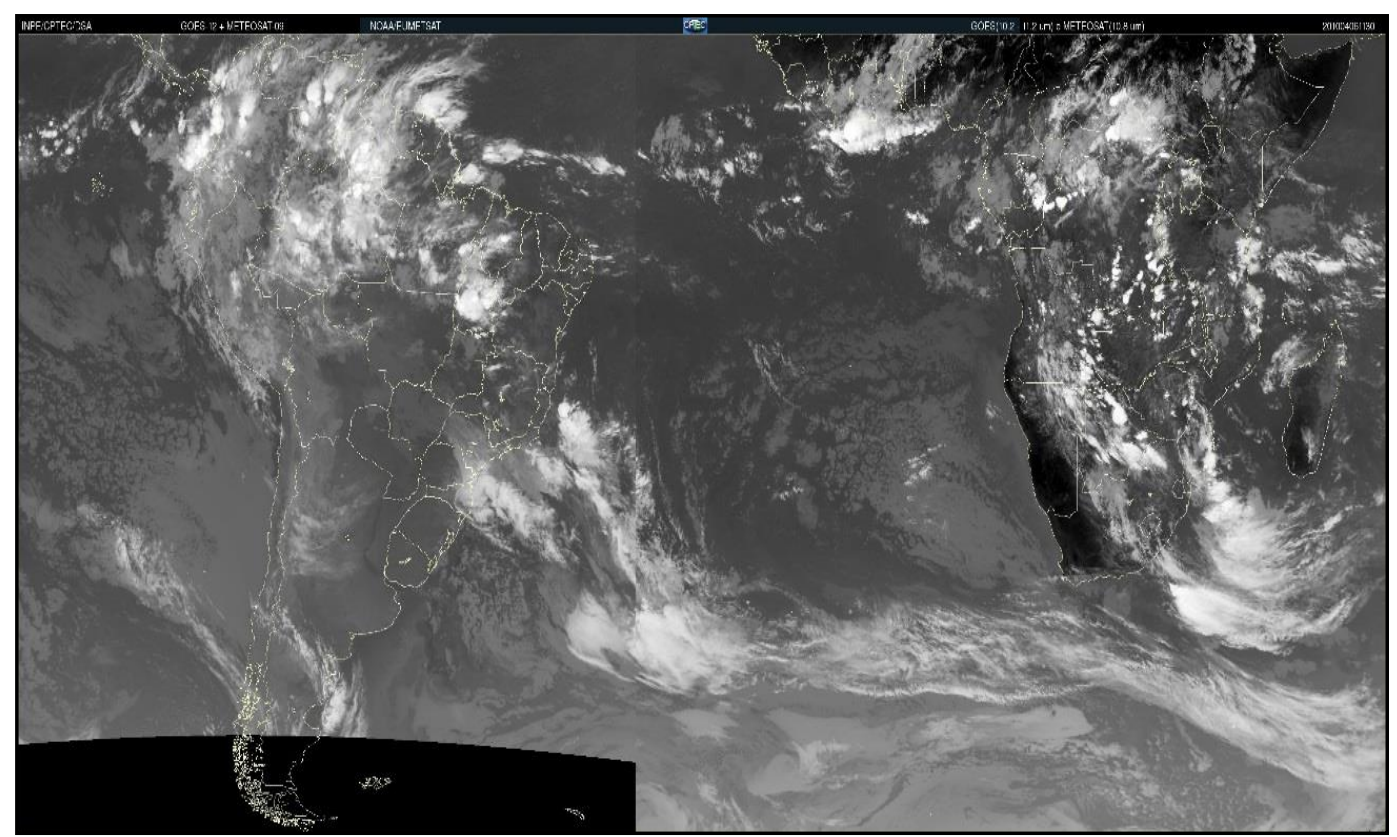

Fonte: INPE, http://satelite.cptec.inpe.br/acervo/goesmet_anteriores15.jsp?i=br, acesso em 7 de dezembro de 2013.

$\mathrm{Na}$ sequência de imagens dos dias 7 e 8 (figura 4 e 5) ainda nota-se a presença de nuvens, como nos dias anteriores, no entanto observa-se um deslocamento destas em direção ao oceano. Desta forma, entende-se que a configuração de nuvens que ocasionaram as chuvas ao longo dos dias foi se dissipando, apesar de haver registro de precipitação até o dia 10 de abril.

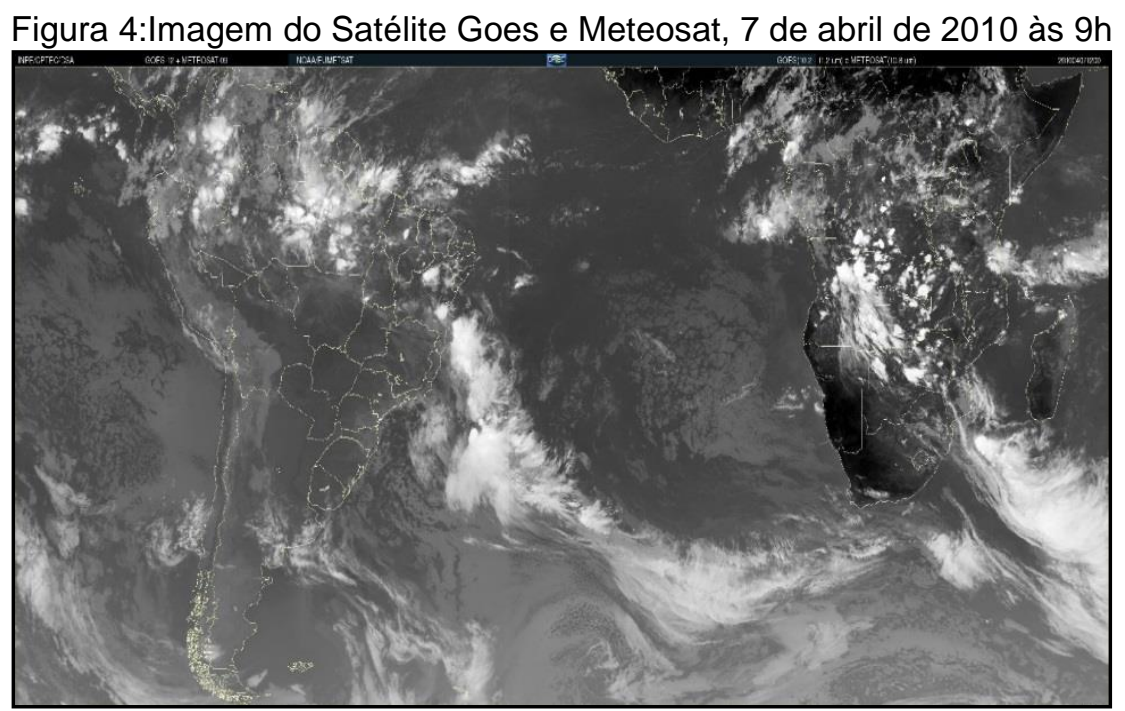

Fonte: INPE, http://satelite.cptec.inpe.br/acervo/goesmet_anteriores15.jsp?i=br, acesso em 7 de dezembro de 2013. 
Figura 5:Imagem do Satélite Goes e Meteosat, 8 de abril de 2010 às 9h

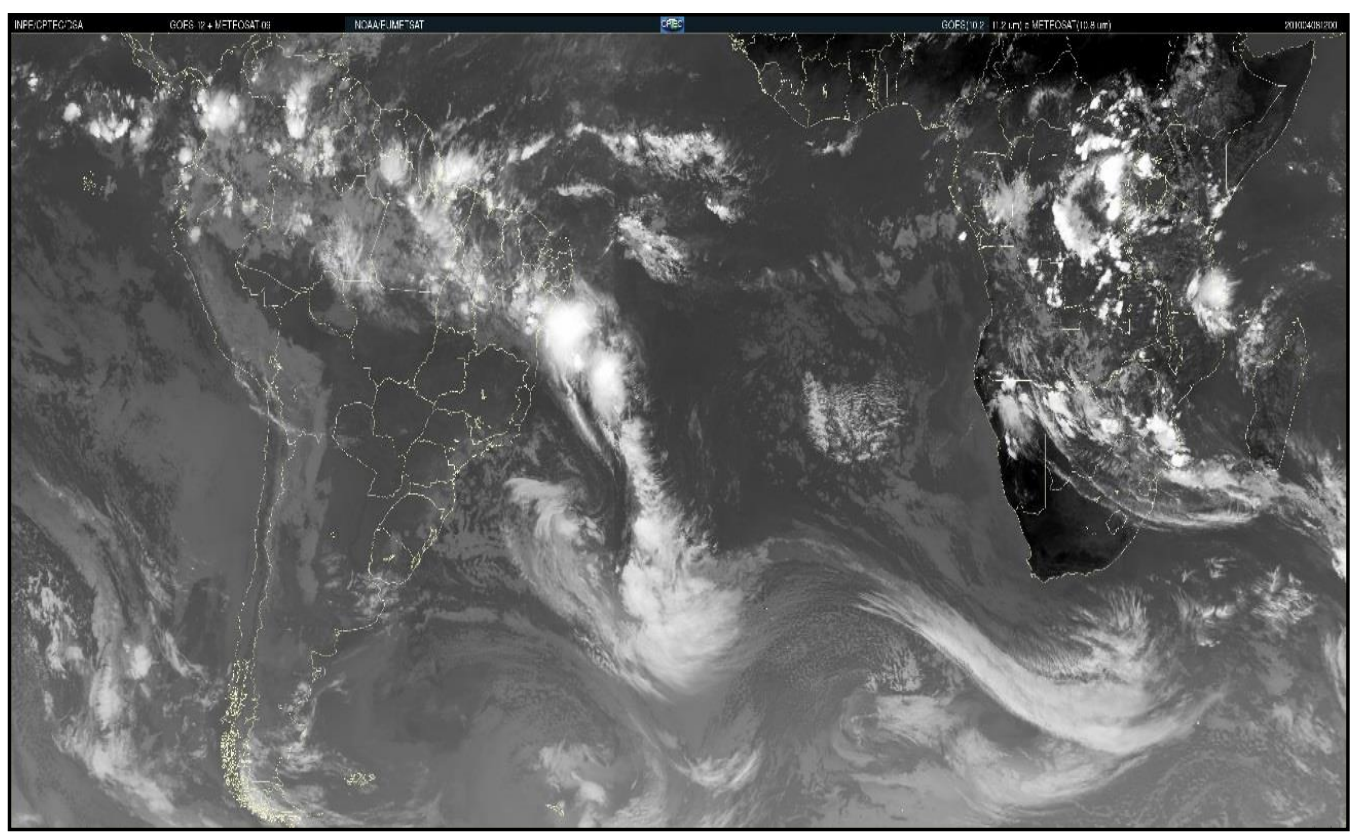

Fonte: INPE, http://satelite.cptec.inpe.br/acervo/goesmet_anteriores15.jsp?i=br, acesso em 7 de dezembro de 2013.

Ao realizar a análise conjunta dos dados pluviométricos e das imagens de satélite foi possível identificar, principalmente a partir das disposições das nuvens, que durante o episódio de chuvas intensas em Niterói em abril de 2010 o sistema atuante era a ZCAS (Zona de convergência do atlântico sul).

De acordo com Rocha e Gandu (1996), as ZCAs são convencionalmente definidas como uma persistente faixa de nebulosidade orientada no sentido noroeste-sudeste, que se estende do sul da Amazônia ao Atlântico Sul-Central por alguns milhares de quilômetros. Fazendo usos de geotecnologias, esse fenômeno climático pode ser identificado por imagens de satélite, exatamente por essa possuir tais características.

\section{RESULTADOS E DISCUSSÕES}

A paisagem na ciência geográfica tem em sua essência o entendimento entre as relações naturais e humanas, mesmo percorrendo vertentes filosóficas distintas. De acordo com Suertegaray (2001) baseada em Bertrand (1968), o conceito de paisagem é tido como uma entidade global, que possibilita a visão 
sistêmica de uma combinação dinâmica e instável dos elementos físicos, biológicos e antropológicos.

O sensoriamento remoto é uma ferramenta que pode ser muito bem empregada na análise da paisagem, uma vez que ele proporciona a visão holística do recorte estudado, além de, a partir de cruzamentos de informações e busca de diferentes imagens temporais, torna possível o entendimento de algumas dinâmicas e processos.

No caso do "Morro do Bumba" pode ser percebido uma mudança brusca na paisagem, como observado nas figuras 6 e 7. Utilizando imagens de alta resolução disponibilizadas gratuitamente pelo Google Earth nota-se a transformação ocorrida na paisagem do bairro Viçoso Jardim a partir do episódio de chuvas de abril de 2010.

Figura 6: "Morro do Bumba" e arredores em fevereiro de 2010.

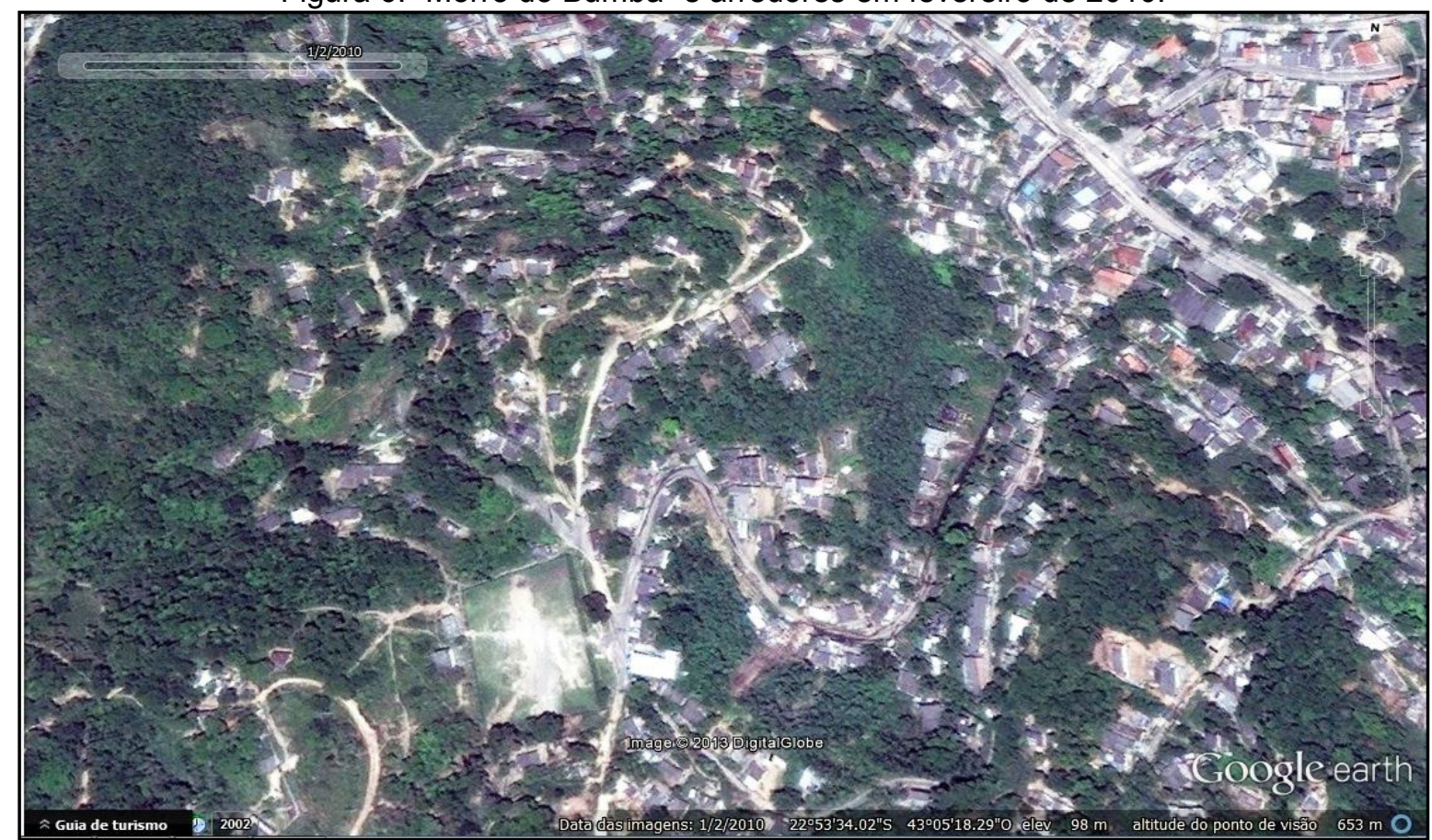

Fonte: Google Earth ${ }^{\mathrm{TM}}$ mapping service/NASA/TerraMetrics copyright (acesso: 05 de dezembro de 2013). 
Figura 7: "Morro do Bumba" e arredores em fevereiro de 2011

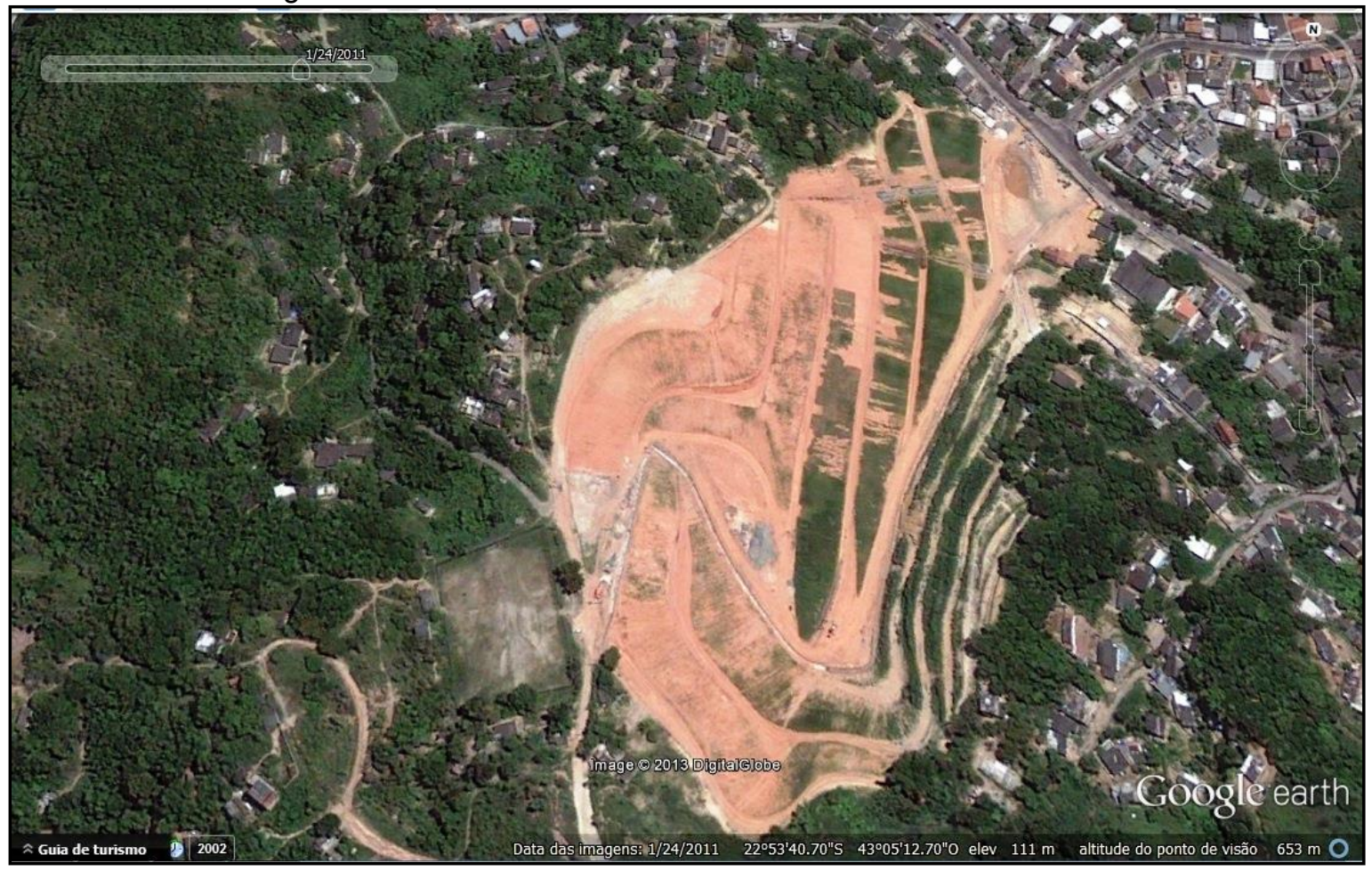

Fonte: Google Earth ${ }^{\mathrm{TM}}$ mapping service/NASA/TerraMetrics copyright (acesso: 10 de abril de 2010).

De uma paisagem densamente ocupada ao longo das vias e com alguns pontos de vegetação observada em 2010, passa-se a ser visualizada uma área composta somente por solo exposto em 2011. Essa alteração foi o resultado do evento já abordado anteriormente e que reforça Santos (2006, p. 95) ao dizer que [...] os eventos mudam as coisas, transformam os objetos, dando-Ihes, ali mesmo onde estão, novas características.

Todavia, o homem como agente transformador não pode ser excluído e nem negado nessa escala de análise, visto que fatores culturais, sociais, políticos e econômicos podem induzir uma determinada parcela da massa populacional a buscar nas áreas de risco a única alternativa viável para uma das necessidades humanas que é o abrigo. Nesse sentido Santos Filho (2011) relata que desastres naturais, como o ocorrido no Morro do Bumba, são reflexos da expansão desordenada dos ambientes urbanos que causam severas alterações nas dinâmicas natureza como o clima, a biosfera, a ecologia, regime hídrico e geomorfologia.

As imagens orbitais auxiliam na análise da paisagem após o evento extremo de forte precipitação em um terreno densamente acidentado e ocupado, por isso o 
deslizamento de massa não pode ser visto apenas de uma ótica natural, pois em muitos casos a combinação de forte precipitação, alta declividade e ação antrópica pode dinamizar e até mesmo acelerar os processos naturais ampliando a sua magnitude.

\section{CONCLUSÃO}

De forma sucinta e breve este trabalho buscou fazer uma análise relacional entre um evento climático extremo, sua origem e suas consequências. Através de análises de imagens de satélites meteorológicos (Goes e Meteosat) e terrestres (Google Earth) tentou-se compreender a gênese climática do episódio de deslizamento ocorrido no mês de abril de 2010 na cidade de Niterói e sua consequência na paisagem do local.

A partir das imagens do satélite Goes e Meteosat foi possível detectar que durante os dias de chuvas estudados esteve atuando sobre a região uma ZCAS, que normalmente ocasiona longos períodos de intensas precipitações.

Sabe-se que existem outros condicionantes que levaram a ocorrência deste deslizamento de terras no "Morro do Bumba", como a ocupação desordenada da vertente, a retirada da vegetação original, a utilização antiga daquele lugar como um depósito de lixo do município, entre tantas outras.

É de conhecimento também que os meios midiáticos comumente "criminalizam" fatores naturais, como as chuvas, e os denominam como "responsáveis" por desastres como estes. No entanto, vale destacar que durante os meses de verão do hemisfério sul são observados altos índices pluviométricos e a ocorrência de ZCAS e a consequente alteração do regime de chuvas na região é constante.

Os deslizamentos de terra em encostas, têm causas diversas que podem ser relacionadas ao material mobilizado, velocidade e mecanismo do movimento, o modo da deformação, a geometria da massa movimentada, o conteúdo de água, os usos e ocupações do local, ou seja, assim como já foi destacado em tantos outros estudos realizados sobre este evento extremo, não basta apenas "culpar" as chuvas, é necessário averiguar e reavaliar o planejamento urbano. 


\section{REFERÊNCIAS}

ROCHA, A. M. G. C. ; GANDU, A. W.. A Zona de Convergência do Atlântico Sul. Climanálise, São José dos Campos (SP), v. Esp., p. 140-142, 1996.

SANTOS, M.. A Natureza do Espaço: técnica e tempo / razão e emoção. 4ª Ed. EDUSP; São Paulo, 2006.

SANTOS FILHO, R. D. dos. Antropogeomorfologia Urbana. In: Guerra, A. J. T. (org.). Geomorfologia Urbana. Rio de Janeiro. Bertrand Brasil, 2011.

SUERTEGARAY, D. M. A.. Espaço Geográfico Uno e Múltiplo. Scripta Nova (Barcelona), Barcelona, v. 93, 2001. 